\title{
Problematização e ensino de língua materna
}

\author{
Tânia Maris de Azevedo \\ UCS-RS
}

Vania Morales Rowell

FSG-RS

\begin{abstract}
Resumo
Resolver problemas é considerada, hoje, a competência fundamental a ser desenvolvida pelo ser humano. Então: o que significa problematizar? Qual o sentido de problematizar no âmbito do ensino da língua materna? O que pode ser problematizado em termos de língua materna? O que diferencia uma situaçãoproblema de um exercício didático? Como a problematização pode se constituir em um recurso pedagógico a serviço do desenvolvimento das competências de leitura e produção escrita? Ler e escrever de forma competente implica necessariamente usar adequada e eficazmente os recursos de que uma língua dispõe para ser enunciada nas mais diferentes situações de interlocução. Desde essa perspectiva, ensinar a ler e escrever impõe transformar situações enunciativas em situações-problema para cuja resolução sejam fundamentais a aquisição e o domínio de diversos mecanismos linguísticos, bem como o desenvolvimento de competências e habilidades para usá-los de modo adequado e eficaz.
\end{abstract}

Palavras-chave: Problematização, ensino, língua materna escrita

\section{INTRODUÇÃO}

Por mais inquietante que seja, ainda hoje se discute a qualidade do ensino da língua materna. Inquietante, porque, num contexto de inúmeros avanços em todas as áreas do conhecimento humano, era de se esperar que o ensino da língua materna já tivesse encontrado caminhos mais profícuos e que realmente fossem capazes de aprimorar as competências básicas de comunicação dos falantes. No entanto, parece que o ensino do português caminha na contramão de todo o progresso científico e tecnológico. Cada vez mais os alunos dizem (e demonstram) saber menos, principalmente em termos de uso da língua escrita, quer no que tange à leitura, quer no que se refere à produção textual-discursiva. A cada dia, vemos mais e mais manuais didáticos sendo produzidos e veiculados, com a promessa de se transformarem 
em verdadeiros instrumentos para aprendizagens significativas, porém, na mesma medida, acompanhamos o agravamento das dificuldades dos sujeitos em operar com a escrita, como leitores e/ou como produtores ${ }^{1}$.

As teorias linguísticas do texto e do discurso têm progredido bastante em seus estudos, mas muito pouco tem sido adequadamente transposto para as situações de aprendizagem do português. Muito se fala em uso de língua, em constituição do sentido do discurso, em configuração deste ou daquele gênero discursivo, entretanto, muito pouco, ou quase nada desses estudos vai para a sala de aula, quer nos cursos de formação docente, quer, por conseguinte, nos níveis de ensino da Educação Básica. Ainda predomina, nas licenciaturas e nos níveis fundamental e médio, o ensino da gramática da língua escrita, a artificialização, a formalização, a normatização de estruturas morfológicas e sintáticas de uma língua que, do ponto de vista do aluno, não é aquela que ele usa fora da sala de aula e nem mesmo na escola para aquisição de conhecimentos específicos de cada disciplina.

A par disso, há uma corrente de estudos psicológicos e pedagógicos que defende uma aprendizagem voltada não só para a aquisição do conhecimento cultural e historicamente produzido mas também para o desenvolvimento de competências, habilidades e estratégias, para a constituição de efetivos saberes, uma vez que os conhecimentos adquiridos devem poder ser aplicados à resolução de situações-problema, escolares ou cotidianas. Para tanto, propõem uma sistemática de problematização, de modo a que os alunos possam realmente assumir a condição de sujeitos de sua aprendizagem e a tornem significativa, porque produtiva, ou, ao contrário, produtiva, porque significativa.

Essa sistemática já vem a tempos sendo estudada e implementada nas disciplinas de matemática e física, há alguns experimentos também em ciências e estudos sociais, mas pouco se vê da aplicação dessa proposta no processo de ensino-aprendizagem de português.

Cientes dessa realidade e da complexidade nela imbricada, propomos contribuir para o processo de reflexão sobre a problematização aplicada ao ensino de língua materna escrita na Educação Básica. Não delimitaremos neste momento o nível de ensino, por acreditarmos que os pressupostos a serem aqui discutidos podem embasar o ensino do português escrito tanto no Ensino Fundamental quanto no Ensino Médio. Obviamente, serão necessárias adaptações

\footnotetext{
${ }^{1}$ Não é diferente com a língua oral, mas, dados os limites deste artigo, nos restringiremos a tratar da modalidade escrita da língua materna.
} 
de cunho metodológico na medida da progressão dos níveis de ensino, porém as bases da proposta não deverão sofrer alterações substanciais.

Apresentaremos, portanto, a resolução de problemas como um recurso pedagógico capaz de tornar o ensino do português escrito mais eficaz e mais direcionado à sua maior função que é a de instrumentalizar o aprendiz para que este possa desenvolver suas competências de leitura e produção, bem como para que, por meio de um maior domínio de sua língua materna, possa interagir mais eficazmente com os conhecimentos das outras disciplinas curriculares.

Nesse sentido, começamos por discutir nossa concepção de aprendizagem e, por decorrência, de ensino, para, depois, tecer algumas considerações sobre o que se entende por problematização e, ao fim, suas aplicações e implicações pedagógicas no ensino do português escrito.

\section{ALGUMAS CONCEPÇÕES}

A fim de que nossa concepção de aprendizagem seja explicitada, parece-nos necessário trazer à discussão os dois processos de educação que possibilitam ao homem conhecer e, consequentemente, o que entendemos por conhecimento.

Da relação do homem, como sujeito conhecedor, com a natureza e com os outros sujeitos - relação desencadeada pelos conflitos que a sobrevivência cotidiana impõe - surge o processo de educação informal que é o grande responsável pela preservação da cultura e pela consolidação da sociedade.

A educação informal tem por características: (a) a não-sistematicidade, uma vez que não é planejada nem regida por preceitos didático-pedagógicos; (b) a espontaneidade, já que acontece na justa proporção da necessidade, nos diferentes grupos e relações sociais, à medida que os conflitos surgem como elementos perturbadores da estabilidade do indivíduo/grupo; e (c) a circunstancialidade, visto que o processo não tem local e hora estipulados previamente, efetiva-se em qualquer lugar, a qualquer hora, pelo tempo que se fizer necessário. 
Por meio do processo educativo informal, são transmitidos valores, crenças, mitos, informações, enfim, regras de convivência de um grupo, de geração para geração.

Da exigência de organizar e disseminar conhecimentos, de modo a torná-los comuns a grupos maiores, surge a educação formal, ou ensino. Com ambiente e horários pré-fixados, com profissionais especializados, com programas curriculares estabelecidos e material planejado especificamente para esse fim, a educação formal, diferentemente da informal, assume a configuração de processo: (a) sistemático - metódica e metodologicamente organizado para propiciar a aquisição do conhecimento produzido -, (b) programado - com objetivos e ações planejados previamente e conteúdos hierarquicamente dispostos ao longo de um currículo - e (c) situado artificialmente - em oposição à circunstancialidade que define o processo de educação informal, a educação formal tem tempos e espaços definidos, ocorre por meio da criação de ambientes de aprendizagem, antecipando necessidades e conflitos que supostamente fazem parte da vida em sociedade.

A educação formal passaria a ser, então, uma espécie de simulacro do processo educativo informal, no sentido de que tenta antecipar/reproduzir situações conflitivas na forma de situações de aprendizagem, para que o sujeito tenha acesso ao conhecimento historicamente produzido.

É justamente baseadas nessa idéia de simulação, fundante na constituição da educação formal, que propomos a problematização como um dos pilares metodológicos do ensino do português escrito, pois, se o sujeito aprende ao longo de sua vida pelas necessidades que a sobrevivência impõe, se aprende pela constante tentativa de resolver os problemas com que se depara, nada mais coerente que o ensino - ao invés de se fundamentar em exposições infinitas de conteúdos, em repetições e memorizações exaustivas de informações desprovidas de sentido para o aprendiz - se valha da problematização de situações que simulem o cotidiano do sujeito fora da escola para desencadear as aprendizagens a serem efetivadas, conferindo sentido a elas.

Não estamos aqui desqualificando o papel da informação, e da consequente memorização desta, no processo de aquisição do conhecimento. Acreditamos que a problematização pode contribuir significativamente para a retenção do conhecimento efetivamente construído na memória de longo prazo, aquela cujo conteúdo se torna 
indispensável para a aquisição de novos conhecimentos. O que acontece é que a tônica do ensino tem sido o mero repasse de informações - porque destituídas de sentido, logo, de articulação, de processamento -, as quais ficarão retidas na memória de curto prazo, no máximo, até o momento em que forem requisitadas, por exemplo, por uma prova em que o aluno tenha que “devolvê-las”, de preferência, o mais próximo possível das que constam no manual didático. As informações que adquirimos somente por repetição e que, mesmo assim, ficaram registradas em nossa memória remota (aquelas definições, fórmulas ou regras que nos acompanham até hoje), por não terem sido fruto de uma construção, por não terem se configurado como conhecimento construído, na maioria das vezes, não se constituem objeto de aplicação na resolução de problemas, não conseguimos lançar mão delas para resolver nossos problemas.

O conhecimento não advém do mero arquivamento de informações, é resultado de uma interação do sujeito com o objeto a ser conhecido. Não há transmissão de conhecimento, mas reconstrução, ressignificação do objeto de conhecimento pelo sujeito por meio da ação, da interação, que se faz, por sua vez, pela linguagem.

Como diz Luckesi (1989, pp. 47-48),

O conhecimento é o produto de um enfrentamento do mundo realizado pelo ser humano que só faz plenamente sentido na medida em que o produzimos e o retemos como um modo de entender a realidade, que nos facilite e nos melhore o modo de viver, e não, pura e simplesmente, como uma forma enfadonha e desinteressante de memorizar fórmulas abstratas e inúteis para nossa vivência e convivência no e com o mundo.

É a partir de um acontecimento que se institui como desafio ao sujeito que o processo de conhecer entra em ação, ou seja, que o sujeito, pela interação com outros sujeitos e com as informações - objeto de conhecimento -, constrói uma rede de relações entre essas informações e delas com a situação-problema, interpretando-as e convertendo-as em possibilidades de solução ou de minimização do problema instituído.

O produto desse processo, independentemente da efetiva solução do problema, é o que concebemos como conhecimento. Uma vez que essa rede de relações estabelecida foi incorporada pelo sujeito, poderá ser o alicerce de novas relações na busca de outras soluções para outros conflitos. A cada evento que se apresenta ao sujeito cognoscente, ele localiza e mobiliza o que já assimilou, ressignifica e reconstrói o conhecimento que já possui e, buscando novas informações, realizando novas interações, incorpora novas redes de relações 
ao seu conhecimento prévio, ampliando-o, redimensionando-o e/ou sedimentando-o para a solução de novos problemas.

Assim, sucessiva e recursivamente, o conhecimento vai sendo construído, aprofundado, ampliado, e o sujeito vai se tornando mais autônomo, mais senhor de suas interpretações e ações sobre o mundo e sobre si mesmo.

Cabem aqui algumas considerações sobre a distinção que estabelecemos entre informação, conhecimento e saber. Por informação entendemos todo e qualquer dado concreto ou abstrato a que o indivíduo tenha acesso por qualquer um de seus cinco sentidos ou pelo raciocínio na interação que faz com outros indivíduos ou com o ambiente. O que chamamos conhecimento é o resultado da organização, da estruturação, da hierarquização das informações, as quais, cognitiva e, portanto, individualmente, são processadas pelo sujeito cognoscente; ou seja, conhecimento é o que resulta da rede de relações que o sujeito constrói sistemicamente entre as informações que lhe são significativas. Já o saber é constituído circunstancialmente na aplicação dos conhecimentos construídos à resolução de problemas, implicando, por isso, o desenvolvimento, por parte do sujeito conhecedor, de competências e habilidades específicas a cada situação; implica a articulação e a aplicação de conhecimentos, bem como a mobilização de competências e habilidades para resolução de problemas. Resumindo: o saber articula conhecimentos, competências e habilidades; o conhecimento pressupõe o estabelecimento de relações entre informações significativas; e a informação é, como diz Morin (2002, p. 16 e 18), “a matéria-prima do conhecimento”.

Se o ato de conhecer pressupõe a construção de uma rede de informações interconectadas, faz-se necessário aprender a tecer essa rede. A aprendizagem, aqui, é vista como o desenvolvimento de competências/habilidades essenciais ao ato de conhecer como as de observar, comparar, classificar, analisar, sintetizar, interpretar, criticar, descobrir, estabelecer relações.

Aprendizagem, hoje, precisa ser entendida muito mais como a construção reflexiva do conhecimento do que como a associação ou reprodução de conhecimentos já elaborados. O mundo atual requer dos aprendizes que cada vez mais se tornem (re)construtores de conhecimentos, ao invés de serem ávidos consumidores de verdades absolutas. 
Segundo Pozo (2002), existem pelo menos três tipos de aprendizagem: a aprendizagem verbal, a aprendizagem de procedimentos e a aprendizagem conceitual.

A aprendizagem verbal diz respeito à incorporação de fatos e dados à nossa memória, sem lhe dar necessariamente um significado - um saber dizer. A aprendizagem de procedimentos refere-se à aquisição de habilidades ou estratégias para realizar coisas concretas - um saber fazer. A aprendizagem de conceitos concerne à atribuição de significado aos fatos, compreendendo as relações entre eles e interpretando-os de acordo com um marco conceitual, assimilando uma informação nova a conhecimentos prévios, o que fará com que sejam produzidas mudanças nas estruturas de conhecimento, gerando conceitos mais específicos, por processos de diferenciação, ou princípios mais gerais, por processos de generalização.

É fundamental a todo professor reconhecer esses diferentes tipos de aprendizagem para que possa agir como um participante significativo dessas interações, um verdadeiro mediador entre o aprendiz e os diferentes objetos de conhecimento, a fim de poder orientar e instrumentalizar eficazmente os diversos processos de aprendizagem.

De acordo com Moraes (2000, p. 200), a aprendizagem resulta de construções efetivadas pelo sujeito cognoscente por meio de estágios de “reflexão, remanejamento e remontagem das percepções que ocorrem na ação sobre o mundo e na interação com outras pessoas”. A aprendizagem é resultado de um "processo de interação entre o mundo do sujeito e o mundo do objeto, por uma integração ativada pelas ações do sujeito”.

É também fundamental ao professor reconhecer o ensino como uma simulação do processo natural da aprendizagem pela educação informal, pois, naturalmente, uma aprendizagem decorre de uma necessidade, esta criada pelos desafios que conflituam, desestabilizam e mobilizam as estruturas cognitivas do sujeito na sua relação com o mundo. Só assim o professor, mesmo ciente da artificialização que tal simulação implica, poderá aproximar ao máximo a aprendizagem escolar da aprendizagem cotidiana, tornando-a significativa e, portanto, efetiva e eficaz.

Uma forma de criar, no ambiente escolar, necessidades que confiram sentido ao processo de aprendizagem é problematizar situações, conceitos, enfim, é construir situações 
que se constituam, para os alunos, verdadeiros problemas a serem resolvidos e que, para tal, os aprendizes sintam como necessárias determinadas aprendizagens.

O próprio Piaget (1977) defende o desafio como elemento propulsor da aprendizagem. Segundo esse autor, um estímulo só se torna significativo na medida em que há uma estrutura que permita sua assimilação, uma estrutura que acolha o estímulo e que, ao mesmo tempo, produza respostas à sua apresentação. Por meio dos desafios são propostos os estímulos que conduzem à ação consciente do aluno sobre o real, condição necessária do processo de aprendizagem.

Nesse sentido, é essencial ao professor compreender o que significa um problema, quais as etapas de resolução de um problema, o que diferencia um problema de um exercício, como a resolução de problemas pode se constituir em valioso recurso promotor e mesmo consolidador da aprendizagem.

\section{PROBLEMA COMO ALTERNATIVA DE SOLUÇÃO}

Em primeiro lugar, uma ressalva: não distinguiremos aqui problematização de resolução de problemas como duas metodologias diferenciadas, conforme o fazem alguns autores. Para nós, o que importa é que sejam criadas situações que se constituam problemas legítimos para os alunos, que provoquem neles a necessidade de realizar determinadas aprendizagens para poder resolvê-los. Desde essa perspectiva, os dois termos são tomados indiscriminadamente neste artigo.

Comecemos por definir problema. Para Kantowski (1974, apud Brandão, 2005), um problema é uma situação com que o indivíduo se defronta e para cuja solução não possui ferramentas necessárias ou adequadas. Polya (1980, apud Brandão, 2005) afirma que ter um problema significa procurar uma ação apropriada de forma a atingir um objetivo claramente definido, mas não imediatamente atingível. Lester (1983, apud Pozo, 1998, p. 15) define problema como "uma situação que um indivíduo ou um grupo quer ou precisa resolver e para a qual não dispõe de um caminho rápido e direto que leve à solução”. Já para Pozo (1998, p. 
16) “um problema é, de certa forma, uma situação nova ou diferente do que já foi aprendido, que requer a utilização estratégica de técnicas já conhecidas”.

Um problema, então, é uma situação reconhecida pelo aprendiz como tal e, portanto, que o desafia a resolvê-la, mas para a qual não possui uma resposta imediata, nem um procedimento específico que o leve diretamente à solução.

Do ponto de vista do ensino, o problema é visto como uma situação didática na qual se propõe ao sujeito aprendiz uma tarefa que ele não pode realizar sem efetuar uma aprendizagem precisa. Esta aprendizagem, que constitui o verdadeiro objetivo da problematização, se dá ao vencer o obstáculo na realização da tarefa. Assim, a produção impõe a aquisição.

De acordo com Mayer (1983, apud Poggioli, 2007), os problemas têm quatro componentes: as metas, os dados, as restrições e os métodos. As metas constituem o que se deseja alcançar em uma situação determinada; os dados correspondem à informação disponível ao aprendiz para começar a analisar o problema; as restrições são os fatores que limitam o caminho para chegar à solução; os métodos ou operações se referem aos procedimentos utilizados para resolver o problema.

Nesse sentido, resolver um problema não pressupõe apenas compreender a questão proposta, aplicar técnicas ou fórmulas adequadas e obter a resposta correta mas adotar uma atitude de “investigação científica” em relação àquilo que está sendo estudado. Nesse processo, a resposta correta é tão importante quanto à ênfase a ser dada à forma de resolução, permitindo o aparecimento de diferentes soluções, a comparação entre elas e a verbalização do caminho que levou à solução.

Segundo Andre (1986, apud Poggioli, 2007), o processo de resolução de problemas pode ser descrito a partir dos seguintes elementos, considerados na sequência em que aparecem:

- uma situação na qual se quer fazer algo, mas se desconhecem os passos necessários para alcançar o que se deseja;

- um conjunto de elementos que representam o conhecimento relacionado com o problema;

- o solucionador de problemas, o sujeito que analisa o problema, suas metas e seus dados e que forma uma representação do problema em seu sistema de memória; 
- o solucionador de problemas, que opera sobre a representação para reduzir a discrepância entre os dados e as metas;

- o processo de operar sobre uma representação inicial com o fim de encontrar uma solução ao problema. Como parte desse processo de busca da solução, a representação pode transformar-se em outras representações. A busca continua até que se encontre uma solução ou o solucionador de problemas se dê por vencido.

Conforme esse mesmo autor, o solucionador de problemas, ao operar sobre os dados e as metas, utiliza ou pode utilizar os seguintes tipos de informação:

- informação armazenada em sua memória de longo prazo na forma de esquemas ou produções;

- procedimentos heurísticos;

- algoritmos;

- relações com outras representações.

Da complexidade constituinte da resolução de um problema, depreende-se a consistência das aprendizagens que esse processo pode desencadear e consolidar, uma vez que desafia o aprendiz a mobilizar seus conhecimentos prévios e, operando com eles, a buscar aqueles a que ainda não teve acesso, bem como a desenvolver competências e habilidades imprescindíveis ao estabelecimento de relações e à busca de estratégias que a solução do problema pressupõe. Pela resolução de problemas, é possível passar da aprendizagem como construção de conhecimentos para a aprendizagem como efetiva construção e consolidação de saberes.

Andre (1986, apud Poggioli, 2007) assim descreve as etapas de solução de um problema:

1. tomada de consciência do problema - dar-se conta de que existe uma discrepância entre o que se deseja e o que se tem;

2. especificação do problema - realiza-se uma descrição mais precisa do problema;

3. análise do problema - analisa-se as partes do problema e isola-se a informação relevante;

4. geração da solução - consideram-se várias alternativas possíveis;

5. revisão da solução - avaliam-se as possíveis soluções;

6. seleção da solução - escolhe-se aquela que tenha maior probabilidade de êxito;

7. instrumentação da solução - implementa-se a solução; 
8. nova revisão da solução - avalia-se a solução encontrada do ponto de vista da pertinência e eficácia.

Por todas as operações cognitivas imbricadas em cada uma e na sequência dessas etapas, podemos perceber por que a resolução de problemas se configura como uma opção didática capaz de conferir sentido às aprendizagens a serem realizadas pelo sujeito conhecedor. Não por acaso Pozo (1998) afirma que ensinar os alunos a resolver problemas supõe dotá-los da capacidade de aprender a aprender, no sentido de habituá-los a encontrar por si mesmos respostas às perguntas que os inquietam, ao invés de esperar uma resposta já elaborada, visto que a solução de problemas consiste na apresentação de situações que exijam dos alunos uma atitude ativa e um esforço para buscar suas próprias respostas, seu próprio conhecimento.

De acordo com Engel (1997), a resolução de problemas permite praticar abordagens lógicas e analíticas em situações que não são familiares aos aprendizes; ativar seu conhecimento prévio; elaborar novo conhecimento; aprender no contexto em que o aprendizado será aplicado; aprender em um modelo integrado; praticar a aplicação de novos conhecimentos, o raciocínio crítico, a auto-aprendizagem, as habilidades de comunicação e o trabalho em equipe.

Por outro lado, a resolução de problemas impõe ao sujeito mobilizar diferentes tipos de conhecimento, que, conforme Mayer (1992) e Sternberg $(1987)^{2}$, incluem:

- conhecimento declarativo - o conhecimento sobre algo (fato, processo, pessoa etc.);

- conhecimento linguístico - conhecimento de palavras, frases, textos;

- conhecimento semântico - domínio da área referente ao problema;

- conhecimento esquemático - conhecimento dos tipos de problema;

- conhecimento procedimental - conhecimento das operações a serem implementadas para a solução do problema;

- conhecimento estratégico - conhecimento dos tipos de conhecimento e dos procedimentos heurísticos;

Assim sendo, o ensino baseado na solução de problemas pressupõe promover o desenvolvimento de habilidades, bem como a utilização de conhecimentos disponíveis para dar respostas a situações variáveis e diferentes.

\footnotetext{
${ }^{2}$ Ambos apud Poggiolli, 2007.
} 
Mais uma vez fica clara a idéia de que uma tarefa, na forma de um problema, pode propiciar ao sujeito aprendizagens significativas. Mas o que se entende por aprendizagem significativa?

De acordo com Pozo (2002, pp. 58-66), uma aprendizagem significativa deve produzir mudanças duradouras, quer no sentido da substituição, quer da reestruturação de conhecimentos ou comportamentos. Além disso, para ser considerado construtivo, o que se aprende deve poder ser utilizado em outras situações, por transferência ou generalização.

Para tanto, a prática deve adequar-se ao que se tem de aprender; os recursos didáticos, para serem adequados, devem ter por base um equilíbrio entre o que se tem de aprender, a forma como se aprende e as atividades práticas planejadas para promover a aprendizagem.

Consoante Pozo (2002, p. 134), para que efetivamente promovam aprendizagens significativas, as tarefas devem:

- basear-se mais na solução de problemas ou tarefas abertas do que em completar exercícios fechados;

- levar o aluno a conceber a aprendizagem como um processo de se fazer perguntas mais do que de encontrar respostas já acabadas, elaboradas por outros;

- incentivar a ativação e tomada de consciência progressiva de seus próprios conhecimentos e a regulagem dos próprios processos cognitivos na aprendizagem;

- centrar a aprendizagem nos próprios alunos, de forma que a percebam como uma tarefa autônoma pela qual devem se tornar responsáveis;

- avaliar a aprendizagem de forma divergente, incentivando a diversidade de resultados, em vez de buscar um rendimento convergente, homogêneo e uniforme para todos os alunos;

- planejar a aprendizagem como uma tarefa de cooperação social em uma comunidade de saber, em vez de concebê-la como um vício solitário.

No entanto, nem todas as atividades propostas pelo professor são percebidas pelo aluno como um problema a ser resolvido. Não basta que uma situação seja planejada pelo professor como um problema a ser resolvido, é preciso que o aluno a perceba como um problema, caso contrário será apenas mais um exercício.

Pozo (1998 pp. 15-19) diferencia problema de exercício, propondo que reconhecer uma situação como um problema implica não dispormos de procedimentos automáticos que nos permitam solucioná-la de forma mais ou menos imediata, sem exigir, de alguma forma, 
um processo de reflexão ou uma tomada de decisões sobre a sequência de etapas a serem seguidas, ao passo que, concebê-la como um exercício pressupõe dispormos de e utilizarmos mecanismos que nos levem, de forma imediata, à solução.

A realização de exercícios se baseia no uso de habilidades ou técnicas sobreaprendidas (ou seja, transformadas em rotinas automatizadas como consequência de uma prática contínua). [...] um problema é, de certa forma, uma situação nova ou diferente do que já foi aprendido, que requer a utilização estratégica de técnicas já conhecidas. (POZO, 2002, p. 16)

Ainda conforme o mesmo autor, a distinção exercício/problema mais do que uma dicotomia é um continuum, que vai das tarefas meramente reprodutivas, nas quais se pede ao aluno para exercitar, quase sem controle por sua parte, uma técnica ou habilidade já aprendida, àquelas tarefas mais abertas, nas quais o aluno se encontra diante de uma pergunta para a qual deve buscar respostas sem conhecer exatamente os meios para alcançá-las, ou dispondo de várias alternativas possíveis que necessitem ser exploradas.

Mesmo que os problemas sejam mais eficazes para a promoção de aprendizagens significativas, não se pode desconsiderar a importância dos exercícios nesse processo. Em conformidade com Pozo (1998, p. 17), os exercícios permitem “consolidar habilidades instrumentais básicas” para a resolução de problemas. "Se um problema repetidamente resolvido acaba por tornar-se um exercício, a solução de um problema novo requer a utilização estratégica de técnicas ou habilidades previamente exercitadas.”

Meirieu (1998, pp. 173-176) diz que uma tarefa pode passar a ser um problema para o aluno se:

- a tarefa, quando proposta, só puder ser executada ao ser vencido um obstáculo que constitui o verdadeiro objetivo de aquisição para o educador;

- o sujeito, graças à existência de um sistema de restrições, não puder executar a tarefa sem enfrentar o obstáculo;

- o sujeito, graças à existência de um sistema de recursos, puder vencer o obstáculo;

- o aluno for orientado pela tarefa, e o educador, pelo obstáculo;

- a transposição do obstáculo representar um patamar no desenvolvimento cognitivo do sujeito;

- os sujeitos, graças às instruções e aos materiais que lhes são fornecidos, colocarem em ação competências e habilidades que já possuem para adquirir novas. 
Por outro lado, se os alunos não tiverem os meios para transpor o obstáculo ou se o obstáculo já tiver sido transposto, a situação deixa de ser uma situação-problema para se transformar em algo impossível de ser resolvido - no primeiro caso - ou num exercício - no segundo caso.

Como a aprendizagem é (ou deveria ser) o foco do trabalho docente em todos os níveis de ensino, parece lógico que se busquem meios que a promovam e a tornem significativa para o sujeito conhecedor. Por outro lado, como o discurso pedagógico vem apregoando ao longo dos tempos, é preciso que o aprendiz se torne cada vez mais um agente autônomo no seu processo de aprender. Ora, quer-nos parecer que a resolução de problemas venha ao encontro dessas duas grandes finalidades do ensino: promover aprendizagens significativas e tornar o aluno responsável por sua aprendizagem, capacitando-o a aprender a aprender.

Conforme anunciamos anteriormente, o uso da resolução de problemas como estratégia de ensino já não é novidade em algumas disciplinas como a Matemática e a Física, mas, no ensino da língua materna muito pouco, ou quase nada, se vê a respeito. O que significa problematizar em Língua Portuguesa? O que pode ser problematizado em termos de língua materna? Como a resolução de problemas pode se constituir em um recurso pedagógico a serviço do desenvolvimento das competências de leitura e produção escrita?

\section{PROBLEMATIZAR A LÍNGUA MATERNA}

Partimos do pressuposto de que ensinar a língua materna significa ensinar a usá-la, nas modalidades escrita e oral ${ }^{3}$, nas mais diversas situações enunciativas, desde as mais coloquiais até as mais formais, desde as mais cotidianas até as mais acadêmicas. Se partirmos desse pressuposto, é porque acreditamos que, a não ser em situação de uso, o conhecimento da língua não tem sentido, principalmente, nos níveis de ensino da Educação Básica. Ensinar a

\footnotetext{
${ }^{3}$ Embora, como já dissemos, nos circunscrevamos aqui, dados os limites deste trabalho, a tratar do ensino da língua materna escrita, desde o ponto de vista do desenvolvimento das competências de leitura e produção.
} 
metalinguagem, as infindáveis classificações, regras e exceções gramaticais, decididamente, (e os estudantes nos mostram isso todos os dias) não promove o desenvolvimento das competências linguístico-discursivas de recepção ou de produção.

Bakhtin (1986, p. 123) fundamenta esse pressuposto quando afirma que

a verdadeira substância da língua não é constituída por um sistema abstrato de formas linguísticas, nem pela enunciação monológica isolada, nem pelo ato psicofisiológico de sua produção, mas pelo fenômeno social da interação verbal, realizada através da enunciação ou das enunciações. A interação verbal constitui assim a realidade fundamental da língua.

Segundo Bakhtin (2003), não aprendemos a língua materna em dicionários ou gramáticas, a adquirimos por meio de enunciados concretos que ouvimos e reproduzimos em situações reais de comunicação verbal.

Para esse autor (1986, pp. 92-93),

[...] o que importa é aquilo que permite que a forma linguística figure num dado contexto, aquilo que a torna um signo adequado às condições de uma situação concreta dada. Para o locutor, a forma linguística não tem importância enquanto sinal estável e sempre igual a si mesmo, mas somente enquanto signo sempre variável e flexível. Este é o ponto de vista do locutor.

Ora, se é por processos de interação que aprendemos e se esses processos se efetivam, principalmente, via linguagem verbal, parece óbvio e natural que a própria linguagem verbal, oral ou escrita, seja aprendida em situações de interação.

Se a linguagem é o instrumento fundamental do processo de conhecer e se o conhecer pressupõe o aprender, a linguagem desempenha na aprendizagem função igualmente essencial, como mediadora das relações entre o sujeito e o objeto a conhecer, seja na sua vida dentro ou fora da escola.

Nesse contexto, a disciplina de Língua Portuguesa, nos currículos do Ensino Fundamental e Médio, assume, para nós, uma dupla função: a de munir o aprendiz dos mecanismos linguístico-discursivos necessários à leitura e produção dos mais variados gêneros textuais com que poderá se deparar ao longo de sua vida; e a de instrumentalizá-lo linguisticamente para que possa interagir com o conhecimento veiculado pelas demais disciplinas curriculares. Isso porque, segundo Bezerra (2002. p. 38),

[...] o homem transforma e é transformado nas relações produzidas em uma determinada cultura. Mas a sua relação com o meio não se dá de forma direta, ela é mediada por sistemas simbólicos que representam a realidade; e a linguagem, que se interpõe entre o sujeito e o objeto de conhecimento, é o principal sistema de todos os grupos humanos. 
Quando o sujeito se questiona sobre algo, quando mobiliza o que já conhece a respeito do que está investigando e, desde aí, estabelece novas relações a fim de se apropriar desse objeto de investigação e, ainda, quando consegue tomar consciência do caminho percorrido para desvendar o objeto que se lhe põe à frente, bem como do resultado desse desvelamento, 0 faz por meio da linguagem. Como diz Vygotsky (1998), a linguagem dá forma ao pensamento, estruturando-o. É por meio da linguagem que o sujeito interpreta, constrói, reconstrói, ressignifica, redimensiona e socializa o conhecimento.

Para Luria (1987, p. 202),

\begin{abstract}
a presença da linguagem e de suas estruturas lógico-gramaticais permite ao homem tirar conclusões com base em raciocínios lógicos, sem ter que se dirigir cada vez à experiência sensorial imediata. A presença da linguagem permite ao homem realizar a operação dedutiva sem se apoiar nas impressões imediatas e se limitando àqueles meios de que dispõe a própria linguagem. Esta propriedade da linguagem cria possibilidade de existência das formas mais complexas do pensamento discursivo (indutivo e dedutivo), que constituem as formas fundamentais da atividade intelectual produtiva humana.
\end{abstract}

Se a relação entre o conhecer e a linguagem é assim tão estreita e se o ato de conhecer é desencadeado por problemas que desestabilizam as estruturas cognitivas do sujeito e, por isso, o desafiam a adquirir novos conhecimentos, conhecer a própria linguagem, que dá ao sujeito acesso ao conhecimento, implica, igualmente, que sejam problematizados determinados usos para que surja, no aprendiz, a necessidade (e, por decorrência, o sentido) de aprender novas construções linguístico-discursivas.

$\mathrm{Na}$ vida em sociedade, tais problemas e necessidades acontecem naturalmente e decorrem da convivência e das próprias leis da sobrevivência. Na escola, tais situações desafiadoras devem ser simuladas, criadas com o objetivo de desafiar o aluno a aprender. Assim, todos os processos, mecanismos e componentes da modalidade escrita da língua podem efetivamente fazer sentido para o aprendiz, que já é usuário da língua oral e que, portanto, já a adquiriu em uso.

É importante ter claro que a língua, diferentemente das outras disciplinas curriculares, é aprendida, simultaneamente, dentro e fora da escola, portanto, quanto mais similares forem esses contextos de aprendizagem, mais eficaz será o desenvolvimento das competências linguístico-discursivas do sujeito aprendiz.

Da mesma forma, é importante perceber que ao falar em simulação não estamos nos referindo somente à estratégia de criar situações enunciativas que dêem origem à produção de 
gêneros discursivos ${ }^{4}$. A simulação que defendemos começa com a criação de um contexto problematizado que vai delinear situações de uso da língua. Não basta que se diga ao aluno o que deve ser produzido (ou lido), em função de um objetivo e de um destinatário determinados, é preciso que tal produção ou leitura emerjam de um problema a ser resolvido, que se constituam meio, ferramenta, para a resolução desse problema. E mais, tal simulação não implica necessariamente que todos os problemas colocados diante do aluno sejam fictícios, pois, mesmo no âmbito escolar (simulacro por excelência), existem problemas que precisam de solução e que implicarão leituras e produções específicas e de caráter muito mais “real” para o aluno. Uma correspondência, um jornal interno ou informativo comunitário, ou mesmo um mural, pode se configurar uma produção real para o aluno a ser feita na escola, nas aulas de Língua Portuguesa. Tais veículos podem ser usados como o elemento desencadeador de uma unidade de ensino em que vários gêneros tornem-se objetos de aprendizagem ou culminância dessas aprendizagens. Podem ser promovidos debates relacionados ao problema proposto, investigações sobre o tema em questão, trabalhos em grupo - visando à busca de possíveis soluções -, produções (orais e escritas) - apresentando as informações levantadas -, enfim, pode ser promovida uma série de atividades que, além de proporcionar situações para o desenvolvimento de competências - como as de atuar em grupo e avaliar criticamente dados e situações - e habilidades - como as de localizar e acessar informações, resumir, relatar necessárias para a resolução de problemas, culminem na transposição do obstáculo posto pelo problema, ou seja, na produção dos gêneros previstos.

É preciso entender que a problematização aqui proposta, antes de ser tida como uma metodologia de ensino, é por nós concebida como uma atitude constante, logo, cotidiana, do professor frente ao ensino de língua materna. Todas as situações enunciativas, todos os usos da língua, todos os mecanismos, estruturas, sejam ortográficas, morfológicas, sintáticas, semânticas ou textual-discursivas, podem e devem ser objeto de problematização. Trata-se de conduzir o estudo da língua materna como uma constante investigação, seja partindo de textos veiculados em revistas, jornais, ou em materiais didáticos de outras disciplinas, seja partindo dos textos produzidos pelos próprios alunos. Um simples por quê? referindo-se a um determinado uso, a uma dada construção, já faz com que sejam ativadas as estruturas

\footnotetext{
${ }^{4}$ Não nos parece necessário e nem significativo, no contexto deste artigo, distinguirmos gêneros textuais de gêneros discursivos.
} 
cognitivas do sujeito e este se disponha a aprender, sinta a necessidade de tal aprendizagem, atribua sentido ao que pode passar a conhecer.

Essa atitude do professor, além de desencadear e consolidar o espírito investigativo dos aprendizes, fará com que eles tomem consciência dos usos linguísticos que fazem e de outros que podem fazer, tornando-os aptos a assumir sua parcela de responsabilidade sobre suas aprendizagens, isto é, capacitando-os a aprender a aprender.

Embora Bakhtin (1986, p. 93) se refira a um processo linguístico específico, é possível perceber traços dessa proposta em suas palavras quando diz que

[...] o essencial na tarefa de descodificação não consiste em reconhecer a forma utilizada, mas compreendê-la num contexto concreto, preciso, compreender sua significação numa enunciação particular. Em suma, trata-se de perceber seu caráter de novidade e não somente sua conformidade à norma. Em outros termos, o receptor, pertencente à mesma comunidade linguística, também considera a forma linguística utilizada como um signo variável e flexível e não como um sinal imutável e sempre idêntico a si mesmo.

Problematizar na disciplina de Língua Portuguesa significa, então, a partir do conhecimento prévio do aprendiz, simular situações de uso da língua em que o sujeito tenha que buscar e inter-relacionar novas informações - linguísticas, discursivas, contextuais (obstáculos a serem vencidos) -, significativas, porque situadas e a serviço de uma aplicação imediata, indispensáveis à resolução do problema apresentado. E significa também problematizar, pôr em questão, o próprio conhecimento linguístico-discursivo prévio do aluno, a fim de que ele o consolide ou o redimensione, se for o caso.

Com base na distinção problema/exercício feita por Pozo (1998) e Meurieu (1998) e aqui apresentada, os exercícios (que devem suceder aos problemas) têm por finalidade consubstanciar as aprendizagens realizadas e proporcionar a automatização das habilidades desenvolvidas na resolução de problemas.

Outro ponto nos parece essencial: trata-se do papel da língua portuguesa escrita na resolução de problemas de outras áreas do conhecimento. São conhecidas pelos professores de matemática, química, física, geografia, biologia etc. as dificuldades dos alunos em compreender o enunciado dos problemas que lhes são apresentados. Não raras vezes, tais dificuldades não estão situadas no âmbito dos algoritmos, das fórmulas ou dos conceitos específicos dessas áreas, mas nas construções linguístico-discursivas dos enunciados dos 
problemas. São dificuldades de nível lexical, sintático, semântico, textual e/ou discursivo que impedem os alunos de resolver adequadamente os problemas por não poderem recuperar sua unidade de sentido.

Poggioli (2007) menciona o estudo de Carpenter, o qual verificou dois grupos de variáveis verbais que interferem na resolução de problemas matemáticos: as de natureza sintática e as de natureza semântica. Segundo Poggioli,

entre las variables sintácticas se encuentran el número de palabras, la secuencia de la información y la presencia de algunas palabras claves que puedan sugerir la realización de alguna operación matemática. Sin embargo, este autor considera que las variables semánticas son más importantes porque determinan los procesos utilizados por los aprendices en la resolución de problemas aritméticos de tipo verbal. Resolver este tipo de problema implica construir una representación de las palabras del problema y encontrar la solución utilizando las reglas de la aritmética o del álgebra. Una de las dificultades que presentan los individuos en la resolución de problemas de tipo verbal parece ser la representación del problema, es decir, salirse del lenguaje (palabras, frases, oraciones) del problema a una representación mental coherente del mismo. Un subcomponente importante en el proceso de representación para problemas de tipo verbal es la traducción de cada oración.

Uma vez que a língua escrita é um dos principais veículos de interação do sujeito com o objeto de conhecimento, o domínio dessa modalidade da linguagem verbal é de indiscutível importância na resolução dos mais variados tipos de problema. Kintsch (1986 apud Poggioli, 2007) corrobora essa idéia ao dizer que

el lenguaje y el sistema de símbolos constituyen el formato básico de información almacenada en la memoria y éste es un conocimiento que permite comprender y representar el problema. Sin control del sistema simbólico es imposible pretender que un individuo opere satisfactoriamente aunque pueda ser capaz de traducir y comprender la estructura subyacente al problema.

Dadas essas constatações, é fundamental que os professores: (a) tomem consciência de que a falta de domínio da língua materna escrita possa ser para o aprendiz mais um obstáculo a ser transposto na resolução de um problema; e (b) independentemente de serem professores de língua materna, municiem seus alunos com recursos linguístico-discursivos, para que possam compreender os enunciados que constituem o problema e, a partir da consecução satisfatória dessa etapa, possam resolvê-lo adequada e eficazmente.

Ainda um último aspecto. A resolução de problemas, em todas as disciplinas curriculares, possibilita ao aprendiz efetivar a relação teoria-prática na medida em que os conhecimentos por ele construídos, na resolução de um problema, são de imediato aplicados. Na verdade, um problema (prática) põe o sujeito conhecedor diante da necessidade de adquirir novos conhecimentos (teoria) para que possa resolvê-lo (prática). Assim, fica assegurado pela 
resolução de problemas o processo ação-reflexão-ação, tão almejado pelos professores por acreditarem ser o processo fundamental de solidificação das aprendizagens.

Diante de tudo o que a resolução de problemas significa para o processo de aprendizagem, é imprescindível o aprofundamento de estudos nessa área assim como a produção de material didático que possa subsidiar o trabalho docente de problematização da aquisição da língua materna escrita.

\section{REFERÊNCIAS}

Bakhtin, M. (1986). Marxismo e filosofia da linguagem. São Paulo: Hucitec. . (2003). Estética da criação verbal. São Paulo: Martins Fontes.

Bezerra, M. A. (2002). Ensino de língua portuguesa e contextos teórico-metodológicos. In A. P. Dionisio, A. R. Machado \& M. A. Bezerra (Orgs.). Gêneros textuais e ensino. Rio de Janeiro: Lucerna.

Brandão, M. J. L. B. (2005). Modelo de Polya e a resolução de problemas ambientais no $1^{\circ}$ ciclo: Conservação das dunas litorais. Tese de mestrado. UMINHO. Disponível em: https://repositorium.sdum.uminho.pt/bitstream/1822/6266/1/Tese.pdf - Acesso em 08/09/2007.

Engel, C. E. (1997). A aprendizagem baseada em problemas (PBL) é somente outra moda? Changing Medical Education and Medical Practices, 12(12), 15-17. Tradução de A. M. Ivama e K. Ito.

Luckesi, C. et al. (1989). Fazer universidade: Uma proposta metodológica. São Paulo: Cortez.

Luria, A. R. (1987). Pensamento e linguagem: As últimas conferências de Luria. Porto Alegre: Artes Médicas.

Meirieu, P. (1998). Aprender... sim, mas como? Porto Alegre: Artmed.

Moraes, M. C. (2000). O paradigma educacional emergente. $6^{\mathrm{a}}$ ed. Campinas, SP: Papirus.

Morin, E. (2002). A cabeça bem feita: Repensar a reforma, reformar o pensamento. Rio de Janeiro: Bertrand Brasil.

Piaget, J. (1977). O desenvolvimento do pensamento. Lisboa: Publicações Dom Quixote. 
Poggioli, L. (s/d.). Estrategias de resolución de problemas. Serie Enseñando a aprender.Disponível em http://www.fpolar.org.ve/poggioli - Acesso em 10/09/2007.

Pozo, J. I. (1998). A solução de problemas. Porto Alegre: Artmed. . (2002). Aprendizes e mestres. Porto Alegre: Artmed.

Vygotsky, L. S. (1998). Pensamento e linguagem. São Paulo: Martins Fontes.

\section{AS AUTORAS}

Tânia Maris de Azevedo é doutor em Linguística Aplicada, pela PUCRS, pesquisadora nas áreas de Semântica Argumentativa e Gêneros Discursivos e docente do Curso de Letras (Licenciatura) e do Programa de Pós-Graduação em Educação (Mestrado), da Universidade de Caxias do Sul - RS. Possui vasta experiência docente na área de Língua Portuguesa, tanto na Educação Básica (Ensino Fundamental e Médio) quanto na Educação Superior (Graduação e Pó-Graduação). E-mail: tmazeved@ucs.br.

Vania Morales Rowell é mestre em Linguística Aplicada, pela PUCRS, pesquisadora na área de Semântica Argumentativa e docente da Escola Superior de Educação e Saúde, da Faculdade da Serra Gaúcha (Caxias do Sul), ministrando disciplinas de Língua Portuguesa Instrumental e Produção Científico-Textual. E-mail: vania.rowell@fsg.br. 